\title{
Minimally invasive aortic valve replacement in octogenarian, high-risk, transcatheter aortic valve implantation candidates
}

\author{
Andrew W. ElBardissi, MD, MPH, Prem Shekar, MD, Gregory S. Couper, MD, and Lawrence H. Cohn, MD
}

\begin{abstract}
Objective: Risk-stratifying algorithms are currently used to determine which patients may be at prohibitive risk for surgical aortic valve replacement, and thus candidates for transcatheter aortic valve implantation. Minimally invasive surgical approaches have been successful in reducing morbidity and improving survival after aortic valve replacement, especially in octogenarians. We documented outcomes after minimally invasive aortic valve replacement in high-risk octogenarians who may be considered candidates for percutaneous/transapical aortic valve replacement.
\end{abstract}

Methods: From 1996 to 2009, minimally invasive aortic valve replacement was performed in 249 consecutive octogenarians. We used the modified European System for Cardiac Operative Risk Evaluation and Society of Thoracic Surgeons score to risk-stratify patients and characterize all early and late results.

Results: The mean age at operation was $84 \pm 3$ (range 80-95) years, and 111 patients (45\%) were male. Twenty-one percent $(n=52)$ had previous cardiac surgery. Operative mortality was $3 \%(n=8 / 249)$. The median modified European System for Cardiac Operative Risk Evaluation (11\%; interquartile range, 6-14) and Society of Thoracic Surgeons score (10.5\%; interquartile range, 7-17) were not predictive of 30-day mortality in this cohort of patients (European System for Cardiac Operative Risk Evaluation c-index $=0.527$, $P=.74$, Society of Thoracic Surgeons score c-index $=0.67, P=.18$ ). Despite their poor predictive power, the Society of Thoracic Surgeons score and European System for Cardiac Operative Risk Evaluation were correlated with each other $(r=0.40, P<.0001)$. Postoperative complications included stroke in 10 patients $(4 \%)$, pneumonia in 3 patients $(1 \%)$, renal failure requiring dialysis in 2 patients $(1 \%)$, cardiac arrest in 2 patients $(1 \%)$, pulmonary embolism in 1 patient $(1 \%)$, and sepsis in 1 patient $(1 \%)$. Follow-up was available for 238 patients $(96 \%)$ and extended up to 12 years. Overall, long-term survival after minimally invasive aortic valve replacement at 1,5 , and 10 years was $93 \%, 77 \%$, and $56 \%$, respectively. There was no significant difference in long-term survival compared with that of a US age- and gender-matched population (standardized mortality ratio, $1.01 ; 95 \%$ confidence interval, $0.76-1.37 ; P=.88$ ). A multivariate Cox-proportional hazards model indicated that increasing age (hazard ratio, $1.10 ; P=.008$ ) and severe chronic obstructive pulmonary disease (hazard ratio, 2.52; $P<.007$ ) were significant predictors of survival. By using these factors, a clinical prediction model $(P=.02)$ was developed and demonstrated that low-risk patients (first quartile prediction score) had $1-, 5-$, and 8-year survival of $94 \%, 84 \%$, and $67 \%$, whereas high-risk patients (third quartile prediction score) had 1-, 5-, and 8 -year survival of $89 \%, 74 \%$, and $49 \%$, respectively.

Conclusions: Patients thought to be high-risk candidates for surgical aortic valve replacement have excellent outcomes after minimally invasive surgery with long-term survival that is no different than that of an ageand gender-matched US population. These data provide a benchmark against which outcomes of transcatheter aortic valve implantation could be compared. (J Thorac Cardiovasc Surg 2011;141:328-35)

Aortic valve replacement (AVR) for the treatment of severe and symptomatic aortic stenosis (AS) is the standard of care. In recent years, however, there has been rapid techno-

From the Division of Cardiac Surgery, Brigham and Women's Hospital, Harvard Medical School, Boston, Mass.

Disclosures: Authors have nothing to disclose with regard to commercial support.

Read at the 90th Annual Meeting of The American Association of Thoracic Surgery, Toronto, Ontario, Canada, May 1-5, 2010.

Received for publication April 16, 2010; revisions received Aug 1, 2010; accepted for publication Aug 23, 2010; available ahead of print Nov 8, 2010.

Address for reprints: Lawrence H. Cohn, MD, Division of Cardiac Surgery, Brigham and Women's Hospital, 75 Francis Street, Boston, MA 02115 (E-mail: 1cohn@ partners.org).

0022-5223/\$36.00

Copyright (c) 2011 by The American Association for Thoracic Surgery

doi:10.1016/j.jtcvs.2010.08.056 logic advancement in percutaneous approaches to achieve aortic valve implantation. ${ }^{1-6}$ However, because of excellent outcomes after AVR even in high-risk patients, ${ }^{7}$ innovative approaches such as transcatheter aortic valve implantation (TAVI) have been reserved for patients with severe AS deemed to be at very high or prohibitive surgical risk. In this inoperable cohort, a recent prospective multicenter TAVI trial demonstrated a procedural success rate exceeding $90 \%$, with a 30-day and 1-year cumulative mortality rate of $10.4 \%$ and $22.1 \%$, respectively. ${ }^{6}$ These statistics are consistent with other single-institution studies that have gained a vast experience in TAVI. ${ }^{5,8}$

The decision-making process that ultimately determines which patients are at prohibitive risk for AVR has recently 


\section{Abbreviations and Acronyms}

$$
\begin{array}{ll}
\text { AS } & =\text { aortic stenosis } \\
\text { AVR } & =\text { aortic valve replacement } \\
\text { COPD } & \text { chronic obstructive pulmonary } \\
& \text { disorder } \\
\text { EuroSCORE }= & \text { European System for Cardiac } \\
& \text { Operative Risk Evaluation } \\
\text { HR } & \text { hazard ratio } \\
\text { MiniAVR }= & \text { minimally invasive aortic valve } \\
& \text { replacement } \\
\text { OR } & \text { odds ratio } \\
\text { STS } & \text { Society of Thoracic Surgeons } \\
\text { STS-PROM = } & \text { Society of Thoracic Surgeons } \\
& \text { Predicted Risk of Mortality } \\
\text { TAVI } & =\text { transcatheter aortic valve } \\
& \text { implantation }
\end{array}
$$

come into question. ${ }^{9}$ Ideally, clinical decision-making would consist of a physician's assessment of a patient's overall health and his/her suitability to tolerate cardiac surgery. In recent years, surgical scoring systems have been developed to use a wide array of preoperative variables in an effort to accurately determine a patient's risk of mortality. ${ }^{10,11}$ The models that have been predominantly implemented into clinical practice are the European System for Cardiac Operative Risk Evaluation (EuroSCORE) $)^{10}$ and the Society of Thoracic Surgeons Predicted Risk of Mortality (STS-PROM) score. ${ }^{11}$ Although some studies have found these models to be highly accurate and predictive of operative morbidity and mortality, ${ }^{12,13}$ there is increasing evidence that these models may be less accurate at predicting outcomes in patients who are at extreme ends of the risk spectrum. ${ }^{14,15}$ Recent studies have found that these scoring systems do not account for clinical and anatomic characteristics (ie, patient frailty and a porcelain aorta ${ }^{6}$ ) that are thought to be highly relevant to a patient's ability to tolerate AVR. As a result, there is concern in the surgical community that reliance on these prediction models may inappropriately direct patients to TAVI when in fact, they may be good surgical candidates.

It is our contention and that of others ${ }^{14}$ that AVR can be performed safely in high-risk patients. ${ }^{14,16-18}$ Although retrospective in nature and limited by treatment bias, studies have shown that AVR in octogenarians can be achieved with an operative mortality as low as $5.9 \%{ }^{17}$ and 1 - and 5-year survivals of up to $90 \%$ and $70 \%$, respectively. ${ }^{18}$ Since the introduction of minimally invasive cardiac surgery by Svensson, ${ }^{19}$ Cosgrove and Sabik, ${ }^{20}$ and our group at Brigham and Women's Hospital, ${ }^{21}$ we have continued to perform the majority of isolated AVRs through a minimally invasive approach (MiniAVR) in almost all circumstances, including reoperations. ${ }^{16-18,22,23}$ Our experience with MiniAVR has demonstrated that patients benefit from decreased length of hospital stay, as well as decreased morbidity and dependence on rehabilitation services after discharge. ${ }^{24}$ As such, we believe these favorable outcomes are likely to be amplified in patients at high risk of perioperative morbidity.

We hypothesized that the current trend in cardiac surgery to move toward percutaneous restorative interventions may have failed to acknowledge the success and safety of open replacement. Furthermore, we believe that current riskprediction models may overestimate risk in appropriately chosen and optimized patients, leading some to recommend interventional techniques over traditional approaches. As such, the purpose of this study is to assess the reliability of the current risk-prediction models for patients undergoing MiniAVR. In addition, we aim to evaluate immediate perioperative outcomes after isolated MiniAVR in octogenarians who might otherwise be considered candidates for TAVI. Finally, our third objective is to document longterm survival to serve as a benchmark for outcomes after TAVI.

\section{MATERIALS AND METHODS}

The main objective of this study is to identify and examine a cohort of patients who would serve as comparable group of patients to those being offered TAVI currently, and potentially in the future. Our inclusion criteria consisted of all patients aged more than 80 years who underwent AVR using a minimally invasive hemi-upper sternotomy (MiniAVR) approach. Exclusion criteria consisted of those who underwent concomitant surgical procedures, because these patients are generally not offered TAVI and outcomes would not be directly comparable to high-risk patients undergoing isolated TAVI.

On the basis of these criteria, 249 consecutive octogenarians underwent isolated MiniAVR by 12 surgeons between August 29, 1996, and March 17, 2009. Preoperative, hemodynamic, operative, and postoperative characteristics were captured via a prospectively collected database modeled after STS national database criteria. ${ }^{11}$ To risk stratify patients, the STSPROM $^{11}$ was calculated for each patient. Because of significant limitations in interpretability of both the additive and logistic EuroSCORE, the modified EuroSCORE ${ }^{25}$ (a distinct score from both the additive and logistic score), which has been shown to enhance the accuracy and clinical relevance of both the additive and logistic EuroSCORE, ${ }^{25}$ was calculated for all patients. Primary end points included all-cause 30-day mortality, 180-day mortality, stroke, sepsis, reoperation for bleeding, need for hemodialysis, and long-term survival. Survival data were obtained from clinical visits and correspondence from consulting physicians. The Brigham and Women's Institutional Review Board approved this study.

\section{Statistical Analysis}

Demographic and other patient-related data were obtained from Brigham and Women's Hospital medical records. Continuous variables are expressed as a mean \pm standard deviation or median with interquartile range (IQR) in situations where covariates are not normally distributed. Categoric variables are expressed as a percentage. Because our prospective clinical research database is modeled after the STS national database, the STSPROM score was directly calculated for each patient according to the most recently released formula. ${ }^{11}$ The logistic and additive EuroSCOREs were calculated after the necessary STS covariate manipulation ${ }^{26}$; these 
TABLE 1. Preoperative, hemodynamic, and operative characteristics

\begin{tabular}{lc}
\hline Preoperative characteristics & \\
Age, y & $\pm 4(80,95)$ \\
Male gender & $111(45 \%)$ \\
Smokers & $124(61 \%)$ \\
Diabetes & $38(15 \%)$ \\
Hypercholesterolemia & $141(57 \%)$ \\
Hypertension & $154(76 \%)$ \\
Prior CVA & $10(5 \%)$ \\
Infectious endocarditis & $8(4 \%)$ \\
Severe chronic lung disease & $31(15 \%)$ \\
Peripheral vascular disease & $34(17 \%)$ \\
Cerebrovascular disease & $26(13 \%)$ \\
Previous cardiac surgery & $52(21 \%)$ \\
Previous CABG & $45(18 \%)$ \\
Previous valve & $14(6 \%)$ \\
CHF & $118(47 \%)$ \\
Angina & $60(24 \%)$ \\
NYHA class & \\
I/II & $93(46 \%)$ \\
III/IV & $110(54 \%)$ \\
Baseline creatinine & $1.29 \pm 0.5$ \\
Renal failure requiring dialysis & $20(8 \%)$ \\
Hemodynamic characteristics & \\
Ejection fraction & $57 \pm 11$ \\
Congestive heart failure & $118(47 \%)$ \\
Mean PA pressure & $24 \pm 9$ \\
Aortic stenosis & $184(91 \%)$ \\
Mean aortic gradient & $50 \pm 20$ \\
Moderate or greater AR & $81(40 \%)$ \\
Operative characteristics & \\
Crossclamp time & $111 \pm 49$ \\
CVA Cere & $71 \pm 28$ \\
\hline
\end{tabular}

$C V A$, Cerebrovascular accident; $C A B G$, coronary artery bypass grafting; $C H F$, congestive heart failure; NYHA, New York Heart Association; $P A$, pulmonary artery; $A R$, aortic regurgitation; $C P B$, cardiopulmonary bypass.

were subsequently converted to the modified EuroSCORE, which has been found to be a more accurate predictor of mortality. ${ }^{25}$ The linear relationship between the STS score and modified EuroSCORE was assessed with a linear regression model and Pearson correlation coefficient. The performance of the modified EuroSCORE and STS-PROM in determining the discriminatory ability of predicted mortality versus actual 30-day mortality was then assessed using a c-index. The c-index is a statistic that represents the area beneath the receiver operator curve with values ranging from 0.50 (random chance with no discriminatory ability) to 1.0 (perfect discrimination). ${ }^{27}$ A Hosmer-Lemeshow statistic was then used to determine model calibration of the EuroSCORE and STS score for our study population.

Univariate predictors of 30-day and 6-month survival were identified and multivariate analyses were performed using an automated stepwise backward covariate selection. Long-term survival analysis was initially performed by comparing survival of the overall patient cohort with expected mortality rates from the US Census Bureau 2002 national lifetables by means of a 1-sample log-rank test ${ }^{28}$; differences between an age- and gender-matched population were assessed by means of a standardized mortality ratio. ${ }^{28}$ We subsequently attempted to build a long-term survival prediction model. Model selection was performed using the approach described by Collett ${ }^{29}$ (pages 80-89) and is briefly described in this article. After univariate analysis for each preoperative and hemodynamic predictor, those with a parameter $P$ value less than .15 were selected for initial entry into the multivariate model. After initial fitting, nonsignificant variables were eliminated using backward selection $(P<.1)$. Nonsignificant univariate predictors were subsequently tested using forward selection $(P=.1)$, and all possible 2-way interactions were tested using forward selection ( $P=.1$ for entering). Finally, all nonsignificant main effects (unless a component of an interaction term) and nonsignificant interactions were removed at a $P$ value less than .05 . The proportional hazards assumption was evaluated for all significant predictors; for those assumptions that did not hold, interaction terms with follow-up time were evaluated to allow for hazard ratio (HR) variation. To assess the discriminatory ability of the final model, a Kaplan-Meier survival curve of patients in the 3 tertiles of the linear predictor was created. SAS version 9.1 (SAS Institute Inc, Cary, NC) was used for statistical analysis.

\section{RESULTS}

As shown in Table 1, mean age at operation was $84 \pm 3$ years (range, $80-95$ years), and $45 \%(n=111)$ of patients were male. Approximately $21 \%(\mathrm{n}=52)$ of patients had previous cardiac surgery. Mean cardiopulmonary bypass and crossclamp times were $111 \pm 49$ minutes and $71 \pm 28$ minutes, respectively. Postoperative complications included stroke in 10 patients $(4 \%)$, reoperation for bleeding in $9 \mathrm{pa}-$ tients $(4 \%)$, pneumonia in 3 patients $(1 \%)$, renal failure requiring dialysis in 2 patients $(1 \%)$, cardiac arrest in 2 patients $(1 \%)$, pulmonary embolism in 1 patient $(1 \%)$, and sepsis in 1 patient $(1 \%)$. Three patients $(2 \%)$ required intra-aortic balloon pump support postoperatively. Mean ventilator duration was $16 \pm 27$ hours, and operative (30-day) mortality was $3 \%(n=8 / 249)$. Reoperative MiniAVR had an operative morality of $3 \%(n=2)$, and postoperative complications included stroke in 4 patients $(8 \%)$, reoperation for bleeding in 3 patients $(6 \%)$, pneumonia in 1 patient $(2 \%)$, cardiac arrest in 2 patients (4\%), and pulmonary embolism in 1 patient $(2 \%)$. Mean ventilator duration was $24 \pm 42$ hours for patients undergoing reoperative MiniAVR.

Univariate analysis of 30-day mortality in the total cohort identified the only predictor of operative mortality to be postoperative stroke (odds ratio $[\mathrm{OR}], 9.5 ; P=.002$ ). The modified EuroSCORE $(11 \%$, IQR $6 \%, 14 \%)$ and STS score $(10.5 \%$, IQR $7 \%, 17 \%)$ were not predictive of 30 day mortality in this cohort of patients (EuroSCORE c-index $=0.527, P=.74$, STS score c-index $=0.67$, $P=.18)$. The Hosmer-Lemeshow statistic for the modified EuroSCORE (chi-square, 6.32; $P=.50$ ) and STS score (chi-square, $8.52 ; P=.38$ ) confirmed that neither scoring system was effective at predicting mortality in this cohort of patients. Despite their poor predictive power, however, the STS score and EuroSCORE were significantly correlated $(r=0.40, P<.0001)$. The linear regression model shown in Figure 1 graphically represents this mathematic relationship (modified EuroSCORE $=6.61+10.01 *$ STS score).

The cumulative incidence of mortality at 6 months postoperatively was $6 \%(n=16)$. Predictors of 6 -month mortality were female gender $(\mathrm{OR}, 3.5 ; P=.003)$, preoperative renal failure (OR, $4.4 ; P=.03)$, severe chronic obstructive 


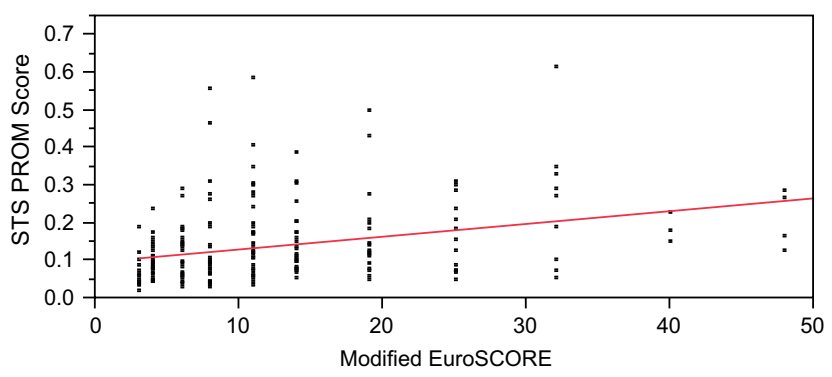

FIGURE 1. Relationship of modified EuroSCORE and STS score. EuroSCORE, European System for Cardiac Operative Risk Evaluation; STS, Society of Thoracic Surgeons.

pulmonary disorder (COPD) requiring oral steroid treatment (OR, 3.62; $P=.02)$, and postoperative stroke (OR, $9.5 ; P=.002)$. A multivariate logistic regression model indicated that when adjusted for each other, female gender $(\mathrm{OR}, 3.5 ; P=.05)$ and severe COPD (OR, 3.33; $P=.04)$ were the most significant independent contributors to 6-month mortality.

Follow-up was available for 238 patients $(96 \%)$ and extended up to 12 years $(3.3 \pm 2.7)$. Overall, long-term survival after MiniAVR at 1,5 , and 10 years was $91 \%$, $77 \%$, and $56 \%$, respectively. With the use of 2002 US Census data, there was no significant difference in long-term survival compared with that of an age- and gendermatched population (standardized mortality ratio, 1.01; 95\% confidence interval, 0.76-1.37; $P=.88$; Figure 2). A univariate Cox proportional hazards analysis identified predictors of mortality to be age (HR, 1.10, $P=.09$ ), severe COPD (HR, 2.36, $P=.02$ ), and postoperative stroke (HR, 4.6, $P=.01)$. A multivariate Cox-proportional hazards model indicated that increasing age (HR, $1.10, P=.007)$ and severe COPD (HR, 2.43, $P=.02$ ) were the only significant predictors of survival. By using these factors (Table 2), a clinical prediction model (chi-square, $15.41 ; P=.0005$ ) was developed and demonstrated that low-risk patients (first quartile prediction score) had 1-, 5-, and 8-year survival of $94 \%, 84 \%$, and $67 \%$, respectively, whereas high-risk patients (third quartile prediction score) had 1-, 5-, and 8 -year survival of $89 \%, 74 \%$, and $49 \%$, respectively (Figure 3).

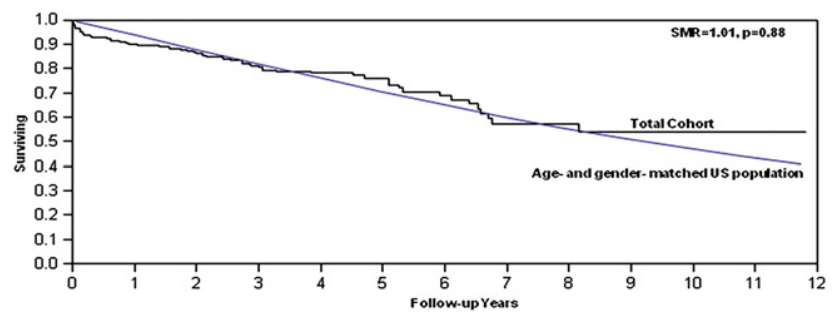

FIGURE 2. Long-term MiniAVR survival compared with an age- and gender-matched population.
TABLE 2. Clinical prediction score characteristics

Clinical prediction score

$\begin{array}{ll}\text { Mean } \pm \text { SD } & 93 \pm 4\end{array}$

First quartile $\quad 89$

Median $\quad 92$

Third quartile $\quad 95$

Calculated by computing $1.1 *$ age $+2.43 *$ severe COPD

$S D$, Standard deviation; $C O P D$, chronic obstructive pulmonary disorder.

\section{DISCUSSION}

We present the findings of a large-volume, single-institution study examining the outcomes after MiniAVR in highrisk patients who may be considered candidates for TAVI. On the basis of these results, MiniAVR in the current era can be safely performed in high-risk octogenarians with a low incidence of morbidity and mortality. These results are discrepant with current statistical mortality scoring systems that suggest many of these patients would be at high or prohibitive surgical risk. In addition, patients in this cohort sustained a low hazard of morbidity and mortality through the immediate postoperative phase in addition to the achievement of an exceptional long-term survival equivalent to that of an age- and gender-matched US population. On the basis of a multivariate analysis, the only variables identified that were found to affect long-term survival were age and COPD. Yet, even patients in the highest risk quartile achieved excellent postoperative and long-term outcomes.

The predicted risk of mortality (both the modified EuroSCORE and STS score) in this cohort was $11 \%$ compared with the observed mortality risk of $3 \%$. This is the largest discrepancy between predicted and observed risk in the literature, ${ }^{14,15,30}$ and reinforces the concern that current scoring systems alone should not be used to dictate which patients are operative candidates. Yet, despite the poor reliability of these prediction models, current TAVI clinical trials have relied on them to identify patients who are at excessive surgical risk. As technology has improved and the cumulative experience of institutions specializing in TAVI has increased, the outcomes after TAVI are promising, but not without significant risk. Operative mortality ranges between $8.6 \%$ and $12 \%, 5,6,8,31,32$ and 1 year mortality ranges between $24 \%$ and $26 \%, 5,6,8,31,32$ with other major complications occurring in as many as $15 \%$ of patients. ${ }^{33}$ The outcomes of this study (operative and 1 -year cumulative mortality of $3 \%$ and $9 \%$, respectively) should not be directly compared with those of the TAVI trials because no randomization occurred and our cohort may have been the result of selection bias effectively removing high-risk patients from the study base. Our results do suggest that current models for determining inoperability are unreliable, should be used with caution, and should not unilaterally determine clinical practices, especially in light of the potential to attain the excellent long-term 


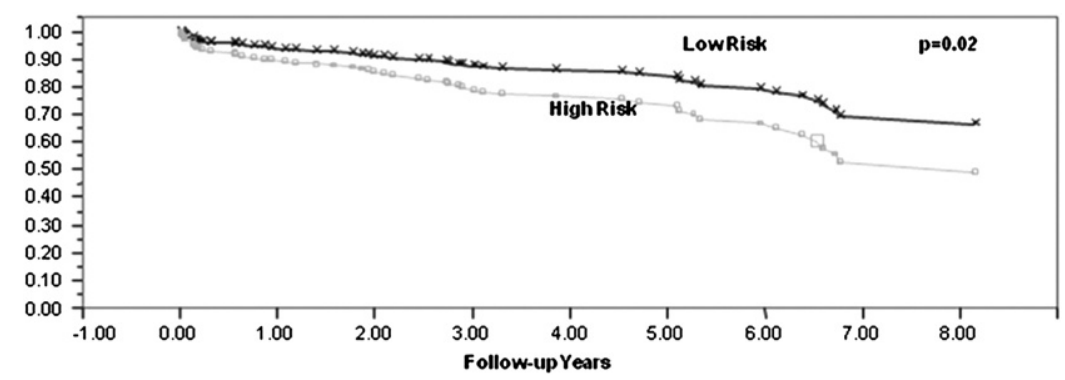

FIGURE 3. Long-term survival clinical prediction model.

surgical outcomes described. In addition to overestimating risk, these models fail to account for a plethora of variables that are critically important in the determination of proceeding with AVR versus TAVI. Some of these variables would include frailty, end-stage liver disease, current quality life, and realistic improvement after surgery. ${ }^{30}$

We chose to use octogenarians as the main inclusion criterion simply because elderly patients have the highest risk profile. One study have found that as many as $40 \%$ of patients aged more than 70 years were denied cardiac surgery $^{34}$ because of their age. The European Heart Survey, which was conducted in 25 countries and 92 institutions, found that approximately $30 \%$ of patients were denied aortic valve surgery with age being the one of the most significant determinants; patients aged more than 80 years were approximately twice as likely to be denied surgery than all others simply on the basis of their age. ${ }^{9}$ The reluctance to operate on elderly patients is likely to increase referrals to TAVI despite increasing evidence that AVR in octogenarians and nonagenarians is both safe and confers excellent outcomes. Comparable to the results of this analysis, a recent study found that patients aged more than 80 years who underwent AVR had 1-, 2-, and 5-year survival of $87 \%, 78 \%$, and $68 \%$ compared with $52 \%, 40 \%$, and $22 \%$, respectively, in those who were denied surgery. ${ }^{7}$ Moreover, survivors achieve a quality of life that is no different than that of the general population. ${ }^{35}$

Although there has been evidence that octogenarians undergoing AVR have survival that is similar to the general population, ${ }^{36}$ this is the first contribution to the scientific literature to demonstrate that survival after AVR in octogenarians is not statistically different than that of an age- and gender-matched US population. This result further emphasizes that AVR should be strongly encouraged when there is confidence that the patient will survive past the immediate postoperative phase of care. The only predictor of operative mortality in this cohort was postoperative stroke; a finding that has been reported in other series examining outcomes after AVR in octogenarians. ${ }^{16}$ Six-month mortality was predicted by female gender and the presence of severe COPD, whereas long-term survival was predicted by both age and severe COPD in a multivariate analysis. Yet, even in patients in the upper tertile of long-term mortality risk, survival was excellent. As such, we failed to identify a subgroup of patients in this cohort in whom TAVI may have been a more appropriate intervention. This reaffirms that AVR can and should be offered in carefully selected highrisk patients.

Since we first adopted minimally invasive cardiac surgery in 1996, it has become our approach of choice when anatomically feasible. As such, we chose to include only patients who underwent isolated aortic valve surgery via a minimally invasive approach to minimize confounding by approach and confounding secondary to concomitant procedures. The partial mini-upper sternotomy, which reduces surgical trauma, has been shown to be associated with a lower incidence of postoperative stroke, myocardial infarction, and length of stay, with a greater proportion of patients being discharged without the need for rehabilitation services. ${ }^{24}$ Although this cohort study lacks a comparison group, it is plausible that the outcomes described may have been attained in part because of the added benefits of minimally invasive surgery in a group of patients who are more susceptible to postoperative morbidity and mortality. Thus, although minimally invasive surgery has been well accepted as advantageous, this study confirms its feasibility, beneficial impact on postoperative outcomes, and long-term survival in high-risk patients requiring AVR.

\section{Limitations}

We present the single-institution findings after MiniAVR in high-risk octogenarians. The intent of this analysis was 2fold. First, we aimed to demonstrate that in the current era, risk-prediction models overestimate the risk of surgery and thus should not be used to determine which patients are at prohibitive surgical risk. Second, we aimed to prove that excellent outcomes after MiniAVR can be achieved in properly selected patients. Inherent in this analysis is that outcomes after MiniAVR are superior to those of TAVI; however, caution should be used when making this conclusion. We do believe, however, that our results provide evidence that current risk-prediction models are not representative of the outcomes after cardiac surgery and thus should not be unilaterally considered when determining optimal intervention of severe AS in octogenarians. In addition, it is important to note that although we describe 
excellent results using a minimally invasive approach, this study was not designed or claim to assert that MiniAVR is superior to traditional AVR via median sternotomy.

\section{CONCLUSIONS}

MiniAVR can be performed safely in octogenarians and can achieve exceptional results when patients are properly selected. Octogenarians who underwent MiniAVR at Brigham and Women's Hospital had a low incidence of morbidity and mortality and achieved long-term survival that was equivalent to that of an age- and gender-matched population. Furthermore, these patients had a preoperative risk of mortality (based on the STS-PROM and modified EuroSCORE) that was approximately 5 times greater than the observed mortality. These results provide a suitable benchmark for TAVI clinical trials and indicate that current risk-prediction models overestimate mortality after cardiac surgery.

\section{References}

1. Cribier A, Eltchaninoff H, Bash A, Borenstein N, Tron C, Bauer F, et al. Percutaneous transcatheter implantation of an aortic valve prosthesis for calcific aortic stenosis: first human case description. Circulation. 2002;106:3006-8.

2. Webb JG, Pasupati S, Humphries K, Thompson C, Altwegg L, Moss R, et al. Percutaneous transarterial aortic valve replacement in selected high-risk patients with aortic stenosis. Circulation. 2007;116:755-63.

3. Walther T, Simon P, Dewey T, Wimmer-Greinecker G, Falk V, Kasimir MT, et al. Transapical minimally invasive aortic valve implantation: multicenter experience. Circulation. 2007;116(11 Suppl):I240-5.

4. Grube E, Schuler G, Buellesfeld L, Gerckens U, Linke A, Wenaweser P, et al. Percutaneous aortic valve replacement for severe aortic stenosis in high-risk patients using the second- and current third-generation self-expanding CoreValve prosthesis: device success and 30-day clinical outcome. J Am Coll Cardiol. 2007;50:69-76

5. Himbert D, Descoutures F, Al-Attar N, Iung B, Ducrocq G, Detaint D, et al. Results of transfemoral or transapical aortic valve implantation following a uniform assessment in high-risk patients with aortic stenosis. J Am Coll Cardiol. 2009;54: 303-11.

6. Rodes-Cabau J, Webb JG, Cheung A, Ye J, Dumont E, Feindel CM, et al. Transcatheter aortic valve implantation for the treatment of severe symptomatic aortic stenosis in patients at very high or prohibitive surgical risk acute and late outcomes of the multicenter Canadian experience. J Am Coll Cardiol. 2010;55: 1080-90. Epub 2010 Jan 22.

7. Varadarajan P, Kapoor N, Bansal RC, Pai RG. Survival in elderly patients with severe aortic stenosis is dramatically improved by aortic valve replacement: results from a cohort of 277 patients aged $>$ or $=80$ years. Eur J Cardiothorac Surg. 2006;30:722-7

8. Webb JG, Altwegg L, Boone RH, Cheung A, Ye J, Lichtenstein S, et al. Transcatheter aortic valve implantation: impact on clinical and valve-related outcomes. Circulation. 2009;119:3009-16.

9. Iung B, Cachier A, Baron G, Messika-Zeitoun D, Delahaye F, Tornos P, et al. Decision-making in elderly patients with severe aortic stenosis: why are so many denied surgery? Eur Heart J. 2005;26:2714-20.

10. Roques F, Nashef SA, Michel P, Gauducheau E, de Vincentiis C, Baudet E, et al. Risk factors and outcome in European cardiac surgery: analysis of the EuroSCORE multinational database of 19030 patients. Eur J Cardiothorac Surg. 1999; 15:816-23.

11. O'Brien SM, Shahian DM, Filardo G, Ferraris VA, Haan CK, Rich JB, et al. The Society of Thoracic Surgeons 2008 cardiac surgery risk models: part 2-isolated valve surgery. Ann Thorac Surg. 2009;88(1 Suppl):S23-42.

12. Kobayashi KJ, Williams JA, Nwakanma LU, Weiss ES, Gott VL, Baumgartner WA, et al. EuroSCORE predicts short- and mid-term mortality in combined aortic valve replacement and coronary artery bypass patients. J Card Surg. 2009;24:637-43.
13. Wendt D, Osswald B, Thielmann M, Kayser K, Tossios P, Massoudy P, et al. The EuroSCORE - still helpful in patients undergoing isolated aortic valve replacement? Interact Cardiovasc Thorac Surg. 2010;10:239-44. Epub 2009 Nov 19.

14. Brown ML, Schaff HV, Sarano ME, Li Z, Sundt TM, Dearani JA, et al. Is the European System for Cardiac Operative Risk Evaluation model valid for estimating the operative risk of patients considered for percutaneous aortic valve replacement? J Thorac Cardiovasc Surg. 2008;136:566-71.

15. Dewey TM, Brown D, Ryan WH, Herbert MA, Prince SL, Mack MJ. Reliability of risk algorithms in predicting early and late operative outcomes in high-risk patients undergoing aortic valve replacement. J Thorac Cardiovasc Surg. 2008;135:180-7.

16. Melby SJ, Zierer A, Kaiser SP, Guthrie TJ, Keune JD, Schuessler RB, et al. Aortic valve replacement in octogenarians: risk factors for early and late mortality. Ann Thorac Surg. 2007;83:1651-7.

17. Florath I, Albert A, Boening A, Ennker IC, Ennker J. Aortic valve replacement in octogenarians: identification of high-risk patients. Eur J Cardiothorac Surg. 2010;37:1304-10. Epub 2010 Feb 1

18. Leontyev S, Walther T, Borger MA, Lehmann S, Funkat AK, Rastan A, et al. Aortic valve replacement in octogenarians: utility of risk stratification with EuroSCORE. Ann Thorac Surg. 2009;87:1440-5.

19. Svensson LG. Minimal-access "J" or "j" sternotomy for valvular, aortic, and coronary operations or reoperations. Ann Thorac Surg. 1997;64:1501-3.

20. Cosgrove DM 3rd, Sabik JF. Minimally invasive approach for aortic valve operations. Ann Thorac Surg. 1996;62:596-7.

21. Cohn LH, Adams DH, Couper GS, Bichell DP, Rosborough DM, Sears SP, et al Minimally invasive cardiac valve surgery improves patient satisfaction while reducing costs of cardiac valve replacement and repair. Ann Surg. 1997;226:421-8

22. Tabata M, Umakanthan R, Cohn LH, Bolman RM 3rd, Shekar PS, Chen FY, et al Early and late outcomes of 1000 minimally invasive aortic valve operations. Eur J Cardiothorac Surg. 2008;33:537-41.

23. Tabata M, Khalpey Z, Shekar PS, Cohn LH. Reoperative minimal access aortic valve surgery: minimal mediastinal dissection and minimal injury risk. $J$ Thorac Cardiovasc Surg. 2008;136:1564-8.

24. Mihaljevic T, Cohn LH, Unic D, Aranki SF, Couper GS, Byrne JG. One thousand minimally invasive valve operations: early and late results. Ann Surg. 2004;240: 529-34.

25. Nissinen J, Biancari F, Wistbacka JO, Loponen P, Teittinen K, Tarkiainen P, et al Is it possible to improve the accuracy of EuroSCORE? Eur J Cardiothorac Surg. 2009;36:799-804.

26. Nashef SA, Roques F, Michel P, Gauducheau E, Lemeshow S, Salamon R. European system for cardiac operative risk evaluation (EuroSCORE). Eur J Cardiothorac Surg. 1999;16:9-13.

27. Zou KH, O'Malley AJ, Mauri L. Receiver-operating characteristic analysis for evaluating diagnostic tests and predictive models. Circulation. 2007;115:654-7.

28. Finkelstein DM, Muzikansky A, Schoenfeld DA. Comparing survival of a sample to that of a standard population. J Natl Cancer Inst. 2003;95:1434-9.

29. Collett D. Modelling Survival Data in Medical Research. Boca Raton, LA: Chapman \& Hall/CRC; 2003.

30. Wendt D, Osswald BR, Kayser K, Thielmann M, Tossios P, Massoudy P, et al Society of Thoracic Surgeons score is superior to the EuroSCORE determining mortality in high risk patients undergoing isolated aortic valve replacement. Ann Thorac Surg. 2009;88:468-75.

31. Rodes-Cabau J, Dumont E, De LaRochelliere R, Doyle D, Lemieux J, Bergeron $\mathrm{S}$, et al. Feasibility and initial results of percutaneous aortic valve implantation including selection of the transfemoral or transapical approach in patients with severe aortic stenosis. Am J Cardiol. 2008;102:1240-6.

32. Ye J, Cheung A, Lichtenstein SV, Altwegg LA, Wong DR, Carere RG, et al. Transapical transcatheter aortic valve implantation: 1-year outcome in 26 patients. J Thorac Cardiovasc Surg. 2009;137:167-73.

33. Rodes-Cabau J, Webb JG, Cheung A, Ye J, Dumont E, Feindel CM, et al. Transcatheter aortic valve implantation for the treatment of severe symptomatic aortic stenosis in patients at very high or prohibitive surgical risk: acute and late outcomes of the multicenter Canadian experience. J Am Coll Cardiol. 2010;55: 1080-90. Epub 2010 Jan 22.

34. Bouma BJ, van den Brink RB, Zwinderman K, Cheriex EC, Hamer HH, Lie KI et al. Which elderly patients with severe aortic stenosis benefit from surgical treatment? An aid to clinical decision making. J Heart Valve Dis. 2004;13: 374-81.

35. Sundt TM, Bailey MS, Moon MR, Mendeloff EN, Huddleston CB, Pasque MK et al. Quality of life after aortic valve replacement at the age of $>80$ years. Circulation. 2000;102(19 Suppl. 3):III70-4. 
36. Likosky DS, Sorensen MJ, Dacey LJ, Baribeau YR, Leavitt BJ, DiScipio AW, et al. Long-term survival of the very elderly undergoing aortic valve surgery. Circulation. 2009;120(11 Suppl):S127-33.

\section{Discussion}

Dr Craig R. Smith (New York, NY). My disclosure is I am the surgical principal investigator for the PARTNER trial.

The authors are to be congratulated for demonstrating remarkably low mortality in octogenarians who are undergoing conventional surgical AVR. The most important implication of these findings is that transcatheter techniques should not be extended to lower-risk patients using age alone as a marker for elevated risk, which is a critical consideration in trial design and in labeling as these devices come out. So I think that is an important contribution.

First, I have a comment and a question. My comment first. I must respectfully object to the implication that MiniAVR as opposed to any other kind deserves partial credit for these excellent mortality results. It would be equally relevant to title this article "AVR in octogenarians done by varsity surgeons from Boston." Numerous retrospectively matched studies to the contrary notwithstanding, there is no randomized controlled evidence that a MiniAVR reduces mortality, there just isn't. Variables such as intensive care unit stay, length of time to discharge, and so forth have been shown, and although probably innocently, they are easily manipulated by enthusiasts.

Now, how could this be so? I will remind you of the famous internal thoracic artery study, internal thoracic artery ligation, in which when restratified according to whether the surgeon was an enthusiast or a skeptic, the enthusiast's patients had $40 \%$ greater relief of angina. So the surgeon is a powerful placebo. So when you are not talking about mortality, very powerful effects. In a more recent study from the University of Cologne, when subjects were told they were given a "lucky" ball to putt with that had been very successful in other people's hands, they sank $35 \%$ more putts. So I think we should be aware of this and remember that patients and referring physicians are listening, and embellishing these outstanding results with a link to a favorite technical trademark only moves that audience from ignorance to superstition.

Now to my question. I think you are right to be proud of achieving $3 \%$ operative mortality in a cohort reported to have an STS score of $14 \%$. This does concern me a little bit for several reasons. I would love to think that this is a benchmark for the TAVI procedure, as you suggest, but I do have some concerns. According to the methods, you included everyone aged more than 80 years having this procedure. As you probably know, in both the New York State database and the STS database, an STS score of 14 represents well less than $5 \%$ of the population. Age more than 80 years adds less than $3 \%$ to the STS score. So I have to wonder, where did those extra 11 points come from? I don't think that $10 \%$ with renal failure would do it, although I could be wrong. Many 90-year-olds have STS scores less than 10. There is a series from Northwestern this year, 190 patients, who seem to be just as unselected as this cohort, in which the average STS score in those aged more than 80 years, there were 41 of them, was 6 . Their operative mortality was $2.4 \%$, similar to what you reported here. In the operable cohort of the PARTNER trial, with an average age of 83 years, the STS score is 11.8 , similar to the $12 \%$ in the Leipzig series you heard this morning. And any center that has been involved in this sort of thing knows that that quickly eliminates the majority of conventional AVR candidates. So I will say again, age more than 80 years adds less than $3 \%$ to the risk score. Now, in aggregate, these observations make an average STS score of 14 extremely surprising for the cohort presented, selected only by age. So how do you explain an average STS score that seems impossibly high in this unselected group?

Dr ElBardissi. That is a great question. Thank you, Dr Smith. It would be difficult for me to go through the details and identify every factor and how that contributed to the STS score of $14 \%$. I will say that $20 \%$ of our patients had reoperations, and, as you mentioned, $10 \%$ of patients had renal failure. This was a particularly sick cohort of patients, and although I would love to have how every factor contributed to that mean score, I just don't have that information right now.

Dr Smith. I wouldn't expect you to.

Dr Robert J. Cusimano (Toronto, Ontario, Canada). Along the lines of the other one, whenever we look at someone for a transcatheter valve, a lot of the times there is a calcified aorta and sometimes there is this word frailty; the reason we accept them is because of frailty. How have you been able to tease the frailty part of the whole thing, and the second question is, how many of your patients had calcified aortas and what do you do with those patients?

Dr EIBardissi. I think it is important to note that our institution is also participating in the PARTNER trial. So this is not meant to be a presentation saying everyone should have an open AVR. I think what you are identifying is what a number of studies have identified, which is there are a number of factors that aren't included in the STS score, such as patient frailty, porcelain aorta, severe liver failure, which generally are thought to contribute significantly to patient mortality, but, again, are not included in the STS score.

Patients who have a completely calcified aorta not amenable at all to cancellation are those whom we would generally refer and include in the PARTNER trial. These are highly select patients. These are obviously patients who underwent the scrutiny of surgeons and cardiologists and were deemed to be operative candidates for surgical AVR. So you can probably say that these are relatively healthy high-risk patients.

Dr Thoralf Sundt (Rochester, Minn). I appreciate that the intent of this presentation is really more to compare surgical AVR with percutaneous AVR, but, predictably, my question, much like Craig's, relates to the value of the "mini" component of this. If I understand correctly, you have sacrificed antegrade perfusion for femoral artery perfusion to gain 3 inches of sternum, and you have a fair number of strokes. Can you tell me anything about those strokes and make me feel better about pumping these people from the groin? These folks are 80 years old, and a lot of them have a lot of calcium in their descending thoracic aortas.

Dr EIBardissi. I can tell you that $4 \%$ of our patients had strokes, and I reviewed all these strokes. The majority of those were small strokes the patient recovered from. There were a couple that were pretty significant strokes. I still don't think a 4\% stroke rate in this cohort of patients, though, is really that significant and should deter someone from providing patients with a long-lasting AVR when they may very well make it through the postoperative phase with no complications. In fact, they would be likely to get through the postoperative phase with no complications. 
Dr Sundt. And I agree with you. I didn't mean to take a shot at you for the $4 \%$ rate in the primary cases or the $8 \%$ in the redos. The real question, though, is, would the stroke rate have been less if they had been perfused from the ascending aorta rather than from the groin? But I appreciate that it is difficult to answer that question.

Dr Bolman. Well, they are perfused antegrade. The patients receive percutaneous venous but central aortic cannulation.

Dr Sundt. It was only percutaneous femoral?

Dr EIBardissi. They are cannulated centrally and perfused centrally except in reoperations, in which case they are perfused peripherally through the femoral artery or they are perfused through the axillary artery, but in all primary operations they are perfused through the aorta.

Dr Sundt. I am sorry I misunderstood. Thank you very much.

Dr Hillel Laks (Los Angeles, Calif). One of the factors that was not discussed in the article on robotic mitral valve surgery that we just heard or in this article on MiniAVR was the effects of these approaches on the brain, on neurocognitive function. One of the great concerns that many surgeons have is the issue of de-airing of the heart at the end of these procedures, which has been shown by transcranial Doppler to shower the brain with microemboli, and the literature is replete with studies retrospectively that have shown $30 \%$ of patients having some neurocognitive dysfunctions. Do you know of any studies that have been done to compare these approaches, and particularly this one, in terms of neurocognitive function recovery, which is particularly pertinent to the old age group?

Dr ElBardissi. As far as neurocognitive function, if we are talking about these transient, diffuse neurocognitive dysfunction episodes, I don't know of any studies. If we are talking about acute events such as strokes or transient ischemic attacks, I can tell you that our institution did a retrospective study that was published in the Annals of Surgery and found no significant difference between the minimally invasive approach and the open approach as far as those acute events are concerned.

Dr Laks. I would like to emphasize that the incidence of clinically apparent strokes underrepresents diffuse brain injury that can result in neurocognitive dysfunction and that can be present as long as 6 months after surgery, and it is thought that many of those may be permanent. I think before we declare that these approaches are superior or equal, a randomized or equivalent type of study needs to be done looking at neurocognitive function both for robotic mitral valve surgery and for other minimally invasive approaches.

\title{
Predictive value of surgical scoring systems in determining operative risk for octogenarians undergoing aortic valve replacement
}

\author{
Marc R. Moon, MD
}

In a retrospective, single-center study, ElBardissi and associates $^{1}$ report the results of isolated aortic valve replacement (AVR) in 249 octogenarians from 1996 to 2009, during which time they performed a minimally invasive approach in almost all patients. This study does not compare the minimally invasive approach with the traditional AVR via median sternotomy, so any conclusions as to the impact of a particular surgical approach would not be reasonable. Therefore, I will make no reference to the specific surgical technique, but refer

\footnotetext{
From the Division of Cardiothoracic Surgery, Washington University School of Medicine, St Louis, Mo.

Disclosures: Author has nothing to disclose with regard to commercial support.

Address for reprints: Marc R. Moon, MD, Joseph C. Bancroft Professor of Surgery,

Division of Cardiothoracic Surgery, Washington University School of Medicine,

660 S. Euclid Ave, Box 8234, St Louis, MO 63110-1013 (E-mail: moonm@

wustl.edu).

J Thorac Cardiovasc Surg 2011;141:335-7

$0022-5223 / \$ 36.00$

Copyright (c) 2011 by The American Association for Thoracic Surgery

doi:10.1016/j.jtcvs.2010.12.015
}

only to AVR in general. The authors' specific aims included the following: (1) demonstrate that AVR can be performed safely in high-risk patients; (2) document long-term survival as a benchmark for future studies; and (3) assess the reliability of two current risk-prediction models, The Society of Thoracic Surgeons Predicted Risk of Mortality (STSPROM) and modified European System for Cardiac Operative Risk Evaluation (EuroSCORE) algorithms, ${ }^{2,3}$ hypothesizing that these current risk-prediction models "overestimate risk in appropriately chosen and optimized patients." Although the authors were successful in addressing specific aims 1 and 2, they may have fallen short in their assessment of the STS-PROM and EuroSCORE risk score algorithms.

\section{SPECIFIC AIM 1}

The authors report operative mortality of $3 \% \pm 2 \%(95 \%$ confidence limit) for octogenarians undergoing AVR during this modern era. Mean ventilator duration was $16 \pm 27$ 